\title{
Graphic Imprints
}

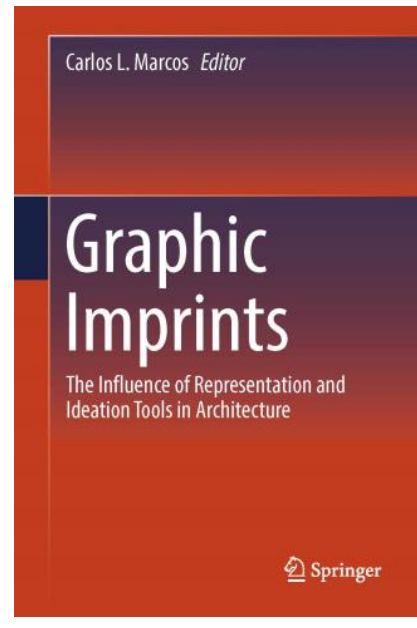

\section{The influence of representation and ideation tools in architecture RESEÑA DE LIBRO por JUAN GUTIÉRREZ, PABLO JEREMÍAS}

Tenemos entre las manos, dispuestos a ser reseñados, los dos volúmenes del libro "Graphic Imprints. The Influence of representation and Ideation Tools in Architecture". Compilan los resultados del XVII Congreso Internacional de Expresión Gráfica Arquitectónica, celebrado en la Universidad de Alicante en 2018. Pesan bastante (1000 páginas el primero, 700 el segundo) y al tacto son muy agradables (tapas duras y satinadas, elegantemente coloreadas). Los volvemos a abrir, releyéndolos esta vez de forma transversal: incalculables los caminos de investigación, los hallazgos y las horas de trabajo: podríamos empezar por los datos objetivos.

Editados por el reconocido investigador y profesor de la Universidad de Alicante, Carlos L. Marcos, y publicados por la prestigiosa Springer International, reúnen a más de doscientos autores (de 18 países distintos) en 137 artículos científicos que se estructuran en torno a siete áreas temáticas. Con un atinado y esclarecedor Prefacio firmado por el editor de los volúmenes, la introducción se completa con dos artículos que, sin pertenecer aún a ninguna de las áreas de investigación propuestas, se complementan excepcionalmente. La primera de las dos Keynotes la firma nada menos que Alberto Campo Baeza. La segunda es fruto del interesantísimo trabajo de Gernot Riether. Alberto es parco, casi poético, en sus reflexiones, e infinito, deslumbrante, en sus dibujos. Gernot, por su parte, hace gala de su profesionalidad con una investigación estructurada académicamente, que se establece desde el principio como referencia de los trabajos digitales publicados. Inmejorable apertura. A continuación se suceden las siete partes de las que consta el libro y que, tal y como nos anuncia Carlos, pivotan alrededor de la idea central del Congreso y surgen, precisamente, para conseguir profundizar con rigor en el debate propuesto. Son las siguientes: 1. Drawing and Project, 2. Drawing, Architecture and Representation, 3. Drawing, Representation and Physicality, 4. Drawing, Mapping, City and Territory, 5. Drawing, Projectivity and Architectural Space, 6. Drawing, Architecture, Perception and Interaction, y 7. Teaching Innovation and Research. Al tiempo que abarcan todo el espectro donde se desarrollan las investigaciones contemporáneas del dibujo, proponen una manera de clasificarlas y, por tanto, relacionarlas y comprenderlas.

Cerramos de nuevo los volúmenes (sonido milenario mediante) pensando cómo sintetizar tantos y tan excelentes artículos. Resultado del trabajo inestimable del comité de revisores y mérito exclusivo de sus autores, se nos antoja imposible hacerles justicia. A buen seguro que usted, lector, sabrá mejor que nosotros ponerlos en valor. Además de ayudarnos a encontrar aquello que estamos buscando, nos atrevemos a afirmar que la publicación que nos ocupa contiene, para todos y cada uno de nosotros (pensadores interesados en la arquitectura o el dibujo) el germen de parte del conocimiento que estamos luchando por construir. No es casual que no encontremos una coda y que los volúmenes cierren abruptamente con las propias investigaciones; el mejor libro está por escribir, parece decirnos Carlos. Su dibujo encontrará, téngalo por seguro, unas referencias indispensables en éste.

Graphic Imprints: The Influence of Representation and Ideation Tools in Architecture. Carlos L. Marcos Alba (ed. Lit.) Vol. 1 y 2. Springer International: Suiza. 